\title{
Dislocated artificial hip as trigger for ST-elevation myocardial infarction
}

\author{
Lucie Kalberer ${ }^{a}$, Peter Wahl ${ }^{b}$, Stéphane Cook ${ }^{a}$ \\ a Department of Cardiology, University and Hospital, Fribourg, Switzerland \\ b Orthopedic Surgery, University and Hospital, Fribourg, Switzerland
}

\section{Clinical image}

A 68-year-old woman was referred for an acute anterior myocardial infarction from the emergency medical services. The prehospital ECG (panel A) demonstrated ST-segment elevation in anterolateral leads and STsegment depression in inferior leads, and the patient was immediately transferred to the catheterisation laboratory. Upon arrival, the patient complained of pain in her right thigh. The paramedics confirmed that the alarm was initially due to suspicion of artificial hip dislocation but once the ambulance arrived, the patient's pain "moved to the chest".

Left arterial femoral access was rapidly gained and the right hip was investigated under fluoroscopy. This confirmed artificial hip posterior dislocation (panel B). Coronary angiogram was then shortly performed and demonstrated a thrombotic occlusion of the proximal part of the left anterior descending artery (panels $\mathrm{C}-\mathrm{E}$, LAD). The patient was administrated 5,000 UI of li- quemine IV and $180 \mathrm{mg}$ of ticagrelor PO. Recanalisation, aspiration's thrombectomy and direct stenting using a dedicated self-expanding drug-eluting coronary stent (Stentys-DES, 3.5-4.5 / $22 \mathrm{~mm}$ ) were promptly performed and led to good angiographical result (Panels F-H). After the coronary intervention, the patient was referred to the on-call orthopaedic surgeon who reduced the hip back into proper position using deep sedation (panel I).

This case illustrates that emotional stress is a significant risk factor for atherosclerotic plaque rupture and subsequent cardiovascular event [1].

Key words: acute ST-elevation; myocardial infarction; plaque rupture; trigger; extrinsic factor

\section{Reference}

1 Schwartz BG, French WJ, Mayeda GS, Burstein S, Economides C, Bhandari AK, et al. Emotional stressors trigger cardiovascular events. Int J Clin Pract. 2012;66:631-9.

\section{Figure}

A 12-lead electrocardiogram showing ST-segment elevation in I, aVL and $V_{1}-V_{3}$ with reciprocal changes in the inferior leads, indicative of transmural anterior wall myocardial infarction.

B The pre- $\mathrm{PCl}$ anteroposterior $\left(0^{\circ} / 0^{\circ}\right)$ fluoroscopy of the right groin demonstrates the artificial hip dislocation.

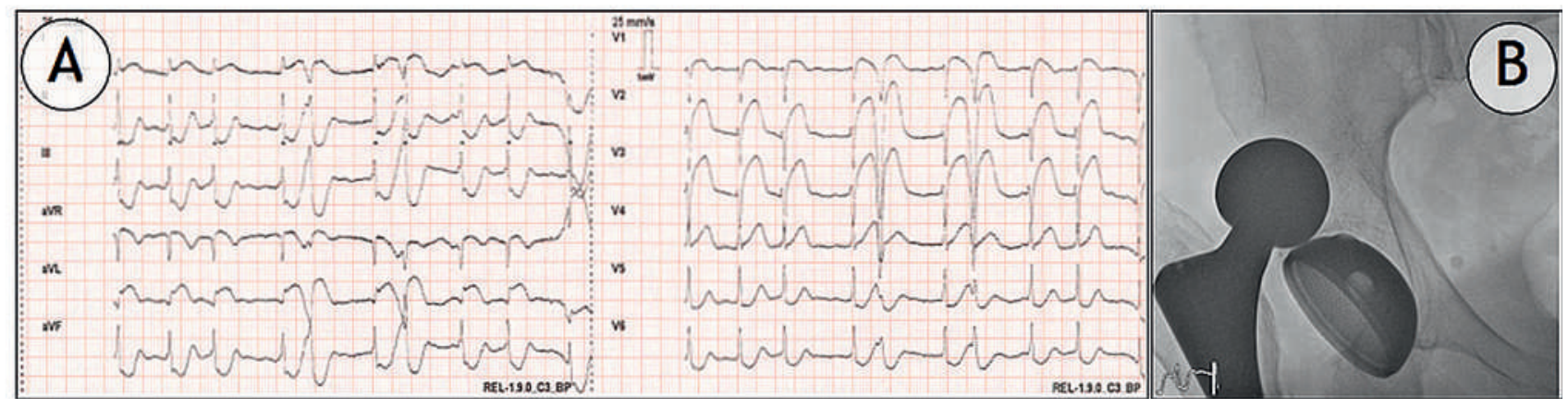

Funding / potential competing interests: No financial support and no other potential conflict of interest relevant to this article were reported
Correspondence:

Professor Stéphane Cook, MD

Department of Cardiology

University \& Hospital Fribourg

$\mathrm{CH}-1708$ Fribourg

Switzerland

stephane.cook[at]unifr.ch 


\section{Figure}

C-H From upper left to lower right: coronary angiograms demonstrating the prompt revascularisation of the thrombotic occluded left anterior descending artery (LAD), result after thrombectomy and direct stenting using one self-expanding drug-eluting coronary stent. Angulations: $0 \%$ caudal $32^{\circ}$ (panels C-F); RAO 39\% cranial 25\% (panel G); LAO 36\% caudal $21^{\circ}$ (panel H).

I Post-PCI x-ray before (up) and after (bottom) successful hip reduction.

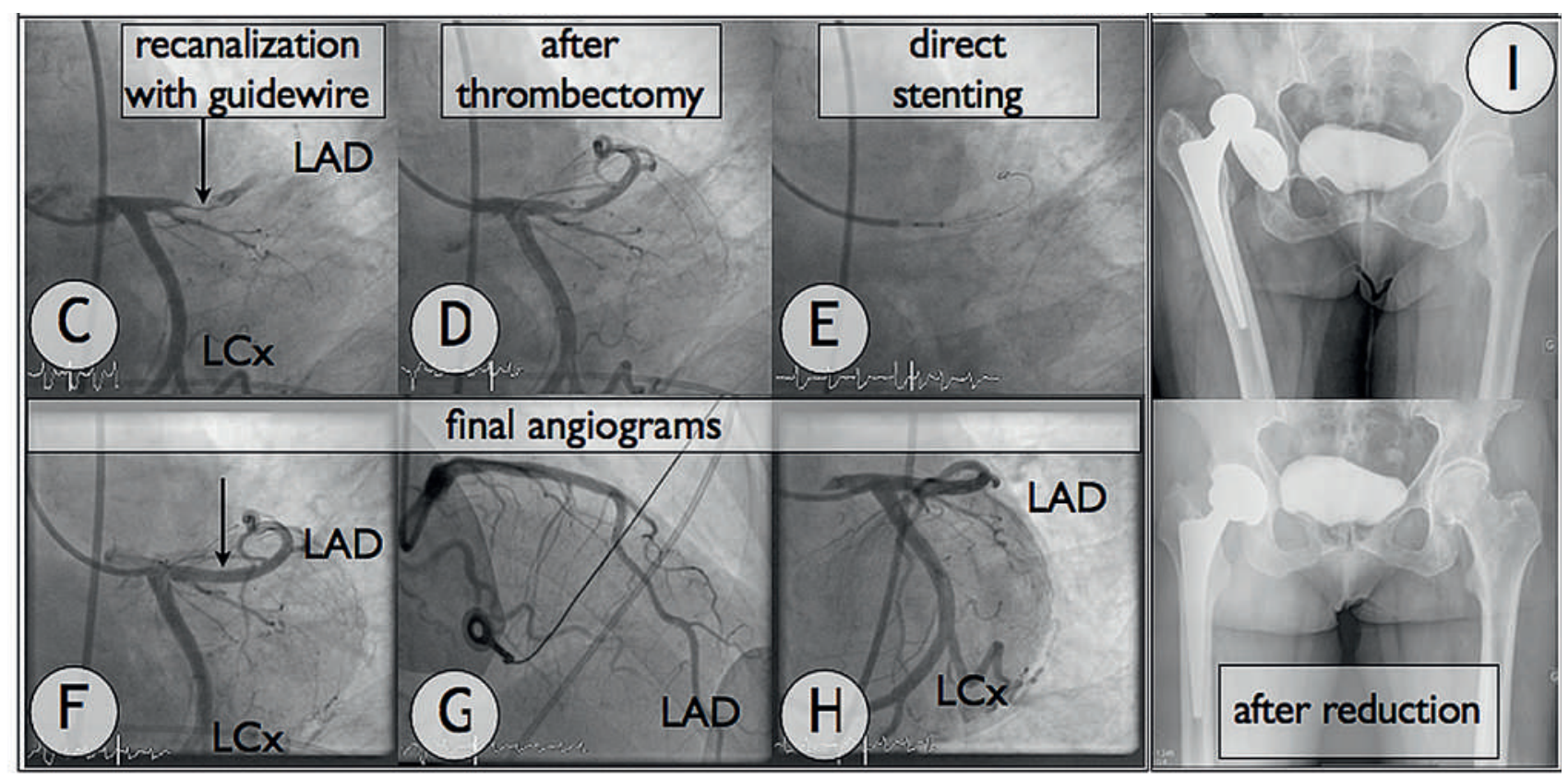

